\title{
Continuous wireless postoperative monitoring using wearable devices: further device innovation is needed
}

\author{
William Xu ${ }^{1 *}\left(\mathbb{D}\right.$, Armen A. Gharibans ${ }^{2}$, lan P. Bissett ${ }^{1}$, Gregory O'Grady ${ }^{1,2}$ and Cameron I. Wells ${ }^{1,2}$
}

To the editor,

We read with great interest the recent article by Areia et al. which highlights the current lack of evidence surrounding the use of wearable monitoring systems to detect deterioration in hospitalised patients.

We agree with the authors' conclusion that the variety of designs, populations, outcomes, and devices "makes it difficult to reach a definitive conclusion". We also agree that this is an emerging area needing further research.

In this meta-analysis, three small randomised controlled trials (RCTs) were included. These RCTS utilised two different devices, the SensiumVitals (The Surgical Company, UK), and the Isansys Lifetouch (Isansys Lifecare, UK) devices. The limited precision of both devices has been noted previously $[1,2]$. Other clinical validation studies of wearable monitoring devices have also demonstrated limited device precision in the postoperative setting [3]. Therefore, any assessment of the ability for devices to detect early deterioration is heavily confounded by inherent limitations of the devices. The possibility for wireless continuous monitoring cannot be realised until the devices used are sufficiently accurate and precise.

Despite the breadth of devices in this field, most wireless continuous monitoring devices are still in their

This comment refers to the article available online at https://doi.org/10.1186/ s13054-021-03766-4

*Correspondence: wxu958@aucklanduni.ac.nz

${ }^{1}$ Department of Surgery, University of Auckland, Building 507, 22-30 Park

Avenue, Grafton, Auckland 1145, New Zealand

Full list of author information is available at the end of the article clinical validation phases [4]. The most immediate challenge in this field is the need for more accurate devices, which needs to be solved through further innovation. Large, well-powered RCTs should not be conducted until robust clinical validation studies have demonstrated adequate device accuracy and precision. Validation studies should also consider the use of continuous monitors as a reference standard rather than nurse-measured observations which are limited in both their frequency and potential accuracy.

Wireless continuous vital signs monitoring likely has benefits that are yet to be apparent. Undetected hypotension, hypoxemia and respiratory depression in the postoperative patient is common and often prolonged; delayed detection of these physiological changes may be a significant contributor to 'failure-to-rescue' and postoperative death [5]. Systems that allow for better detection of patient deterioration have the potential to significantly improve patient care, and rigorous work should be done to explore avenues for improvement. Accurate artefact rejection, better signal processing, and novel sensor technology all may improve device accuracy and utility.

The work of Areia et al. has highlighted the need for further innovations in this space. Device improvements and clinical validation work will shed light on the true value of continuous postoperative monitoring and, most importantly, help confirm if this technology can improve patient outcomes. original author(s) and the source, provide a link to the Creative Commons licence, and indicate if changes were made. The images or other third party material in this article are included in the article's Creative Commons licence, unless indicated otherwise in a credit line to the material. If material is not included in the article's Creative Commons licence and your intended use is not permitted by statutory regulation or exceeds the permitted use, you will need to obtain permission directly from the copyright holder. To view a copy of this licence, visit http://creativecommons.org/licenses/by/4.0/. The Creative Commons Public Domain Dedication waiver (http://creativeco mmons.org/publicdomain/zero/1.0/) applies to the data made available in this article, unless otherwise stated in a credit line to the data. 


\section{Authors' response}

\section{Carlos Areia, Christopher Biggs, Mauro Santos, Neal Thurley, Stephen Gerry, Lionel Tarassenko, Peter Watkinson and Sarah Vollam}

We would like to thank $\mathrm{Xu}$ et al. for their interest in our recent manuscript.

We agree most devices are still in their feasibility and clinical validation stage, with limited evidence on their clinical and cost effectiveness, highlighted in our review and previous research [4].

It is important to consider that the goal of this emerging technology should be to support, and not replace, clinical vital sign monitoring practice, offering another layer of protection between traditional continuous monitoring and manual intermittent observations. Furthermore, although accuracy and reliability of wearable devices are a barrier, most studies have been conducted in healthy volunteers and in comparison with clinical and/or gold standard for continuous measurement [4]; with even less evidence comparing these devices with the standard intermittent manual measurements, the common practice in general wards.

We agree with our colleagues these new monitoring systems should not be used as the "stand-alone" method of vital sign measurement, due to current accuracy and precision limitations. However, well-powered and welldesigned clinical trials, including careful implementation of these new systems, might still be of benefit to support the development and innovation of these technologies, by testing its impact in clinical care as complementary, and not a substitute, to standard practice [6].

\section{Acknowledgements}

Not applicable.

\section{Authors' contributions}

WX (Idea conception, manuscript writing), AAG (manuscript writing, editing and review), IPB (manuscript writing, editing and review), GOG (manuscript writing, editing and review), CIW (Idea conception, manuscript writing). All authors read and approved the final manuscript.

\section{Funding}

Not applicable.

\section{Availability of data and materials}

Not applicable.

\section{Declarations}

Ethical approval and consent to participate

Not applicable.
Consent for publication

All co-authors consent for the publication of the above manuscript in BMC Critical Care.

\section{Competing interests}

Prof. Gregory O'Grady is a member of The University of Auckland Spin-out companies: The Insides Company Ltd and Alimetry Ltd. Dr. Armen A. Gharibans is a member of The University of Auckland Spin-out company Alimetry Ltd. Prof. lan P. Bissett is a member of The University of Auckland Spin-out company The Insides Company Ltd. The remaining authors (William Xu, Dr Cameron I. Wells) have no disclosures.

\section{Author details}

'Department of Surgery, University of Auckland, Building 507, 22-30 Park Avenue, Grafton, Auckland 1145, New Zealand. ${ }^{2}$ Auckland Bioengineering Institute, University of Auckland, Auckland, New Zealand.

Received: 12 October 2021 Accepted: 13 October 2021

Published online: 15 November 2021

\section{References}

1. Duus CL, Aasvang EK, Olsen RM, Sørensen HBD, Jørgensen LN, Achiam $\mathrm{MP}$, et al. Continuous vital sign monitoring after major abdominal surgery-Quantification of micro events. Acta Anaesthesiol Scand. 2018;62(9):1200-8.

2. Downey C, Ng S, Jayne D, Wong D. Reliability of a wearable wireless patch for continuous remote monitoring of vital signs in patients recovering from major surgery: a clinical validation study from the TRaCINg trial. BMJ Open. 2019;9(8):e031150.

3. Breteler MJM, Huizinga E, van Loon K, Leenen LPH, Dohmen DAJ, Kalkman CJ, et al. Reliability of wireless monitoring using a wearable patch sensor in high-risk surgical patients at a step-down unit in the Netherlands: a clinical validation study. BMJ Open. 2018;8(2):e020162.

4. Leenen JPL, Leerentveld C, van Dijk JD, van Westreenen HL, Schoonhoven L, Patijn GA. Current evidence for continuous vital signs monitoring by wearable wireless devices in hospitalized adults: systematic review. J Med Internet Res. 2020;22(6):e18636. https://doi.org/10.2196/18636.

5. Sessler DI, Saugel B. Beyond, "failure to rescue": the time has come for continuous ward monitoring. Br J Anaesth. 2019:122(3):304-6.

6. Areia C, King E, Ede J, Young L, Tarassenko L, Watkinson P, et al. Experiences of current vital signs monitoring practices and views of wearable monitoring: a qualitative study in patients and nurses. J Adv Nurs. 2021. https://doi.org/10.1111/jan.15055.

\section{Publisher's Note}

Springer Nature remains neutral with regard to jurisdictional claims in published maps and institutional affiliations.

\section{Author details}

${ }^{1}$ Department of Surgery, University of Auckland, Building 507, 22-30 Park Avenue, Grafton, Auckland 1145, New Zealand. ${ }^{2}$ Auckland Bioengineering Institute, University of Auckland, Auckland, New Zealand.

Received: 12 October 2021 Accepted: 13 October 2021

Published online: 15 November 2021 